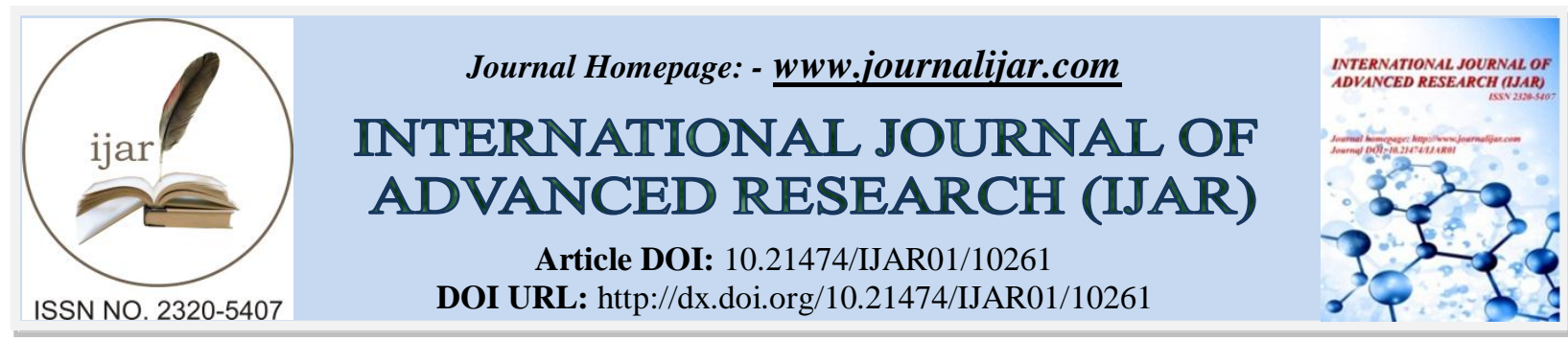

RESEARCH ARTICLE

\title{
THE EFFECT OF SEPTOPLASTY ON MIDDLE EAR PRESSURE AMONG PATIENTS WITH DEVIATED NASAL SEPTUM
}

\author{
Azhar A. Kurban ${ }^{1}$, Saad M. Almuhayawi ${ }^{2}$, Khaled M. Tolah ${ }^{3}$, Maad M. Aljohani ${ }^{4}$ and Hoda Abou Sada ${ }^{4}$ \\ 1. Otorhinolaryngology Resident. \\ 2. Professor and Otorhinolaryngology Consultant. \\ 3. Preventive Medicine Resident. \\ 4. Medical Intern.
}

\section{Manuscript Info}

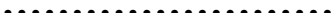

Manuscript History

Received: 14 October 2019

Final Accepted: 16 November 2019

Published: December 2019
Abstract

Septoplasty is a common surgical procedure done in ENT practice for the correction of deviated nasal septum (DNS). Deviated nasal septum causes chronic nasal obstruction which is one of the commonest ENT complains. In our clinical practices eustachian tube (ET) dysfunction may occur due to deviated nasal septum. ET dysfunction lead to changes in middle ear pressure and ventilation. Eustachian tube is a communication between middle ear and nasopharyngeal cavity, and its primary physiological functions are the ventilation of middle ear and equalizes environmental pressure of the external environment with that of middle ear. In addition to protect the middle ear from nasopharyngeal secretions and drainage middle ear secretions into nasopharynx.Few studies are available with varied results. Some studies have reported improvement middle ear pressure after septoplasty. On the other hand, some reported no change in middle ear pressure after septoplasty. In Saudi Arabia, no studies have been done to examine the association between septoplasty and improvement in middle ear pressure. Thus, it is important to monitor the effect of septoplasty on change middle ear pressure and ventilation.This is a prospective analytical study done in the ENT outpatients department of King Abdul-Aziz University Hospital in Jeddah. thirty patients suffering from deviated nasal septum requiring septoplasty by closed technique were admitted to the study. Their age ranged between 18 to 50 years. All patients included in this study underwent full clinical history and examination of the nose, nasopharyngeal and ear. Middle ear pressure assessment was done by tympanometry AZ26 preoperatively, postoperatively after one week and one month postoperatively. Patients suffering from other diseases causing nasal obstruction or disruption Eustachian tube functions or pathology in ears were excluded from this study. The results obtained from our study showed no significant difference in middle ear pressure values between the same side and contralateral of deviated nasal septum before septoplasty and no significant changes in middle ear pressure values on both side of the nasal after septoplasty procedure. 
Copy Right, IJAR, 2019,. All rights reserved.

\section{Introduction:-}

The Eustachian Tube (ET) is a tube that connects the middle ear cavity and the nasopharynx and provides middle ear ventilation [Etigadda et al.,2017]. The physiologic pressure depends on the air transition through the ET and gas diffusion between the middle ear mucosa and systemic circulation [Demirci et al.,2016].

Various methods can be used to assess ET functions and tympanometry is one of them [Rajesh et al.,2017]. We used tympanometry in this study because it is easy to perform and has been widely used for the clinical evaluation of ET functions clinically and in academic research. The relationship between the middle ear, ET, and nasal cavity has been the subject of various studies. An insufficient ventilation of the ET is thought to be an important cause of middle ear dysfunction [Kaya et al.,2018]. It is advocated that nasal, paranasal, and nasopharyngeal pathologies such as deviated nasal septum affect the ET functions, and nasal obstruction causes impairment in the ET functions. However, the study results concerning this topic are controversial. Some authors suggested that middle ear pressure improved after septoplasty while others proposed that there is no difference in middle ear pressure after operation.

The question that arises is can surgical treatment for DNS improve ET function and middle ear pressure and ventilation?

Deviation of the nasal septum may cause nasal obstruction that has the probability of disrupting the functions of the ET which in turn changes the middle ear pressure. Thus, some patients who suffered from nasal septum deviation complained of Eustachian tube dysfunction. Nasal septum deviation affects more than 80 percent of the world population [Kaya et al.,2018] [Roblin et al.,2002]. It is reported that only 33\% of patients with DNS in Saudi Arabia are symptomatic [kamal et al.,2002] .

In Saudi Arabia, no studies have been done to examine the association between septoplasty and improvement in middle ear pressure. Therefore, this study aimed at investigating the role played by septoplasty in changing the middle ear pressure and ventilation.

In this prospective study, our aim was to analyze the effect of correction of nasal septal deviations by septoplasty on ET functions with the use of tympanometry before and after septoplasty.

Aim:

The aim of this study was to investigate the effects of septoplasty on middle ear pressure among patients who were suffering from deviated nasal septum in (KAUH), Jeddah, Saudi Arabia using tympanometry for assessment of middle ear pressure. Such information should increase our knowledge of the benefits of correction of nasal septal deviations in improving middle ear aeration in Kingdom of Saudi Arabia. Furthermore, this study will ultimately contribute to the global information.

\section{Objectives:-}

1. To evaluate middle ear pressure in patients with deviated nasal septum preoperatively on both sides of the deviated nasal septum and contra lateral side.

2. To determines the effect of nasal septal surgery post operatively on middle ear pressure and ET function on both sides of the operated septum.

\section{Literature review:-}

The Role of Septoplasty in Changing Middle Ear Pressure and Ventilation:

According to [Nanda et al.,2017] who conducted on patients with DNS and requiring septoplasty involving 40 adult patients in an aim to find out whether septoplasty leads to improvements in hearing, middle ear pressure and ear symptoms. It was noted that among the common causes of nasal obstruction is a nasal septum deviation which has proved to have negative effects on the middle ear pressure as well as ventilation. During the study, the patients were assessed preoperatively and postoperatively after 2 days, 4 weeks, 8 weeks and 12 weeks. All results were compared and improvement was found in ear fullness symptoms, decrease in incidence of conductive hearing loss and improvement in middle ear pressure after 8- 12 weeks post operatively. Not much improvement was seen before 8 weeks and showed that septoplasty improves hearing and middle ear function after 8-12 weeks of surgery which 
could be because inflammation and edema of nasal mucosa as surgery takes time to heal. It was noted that due to nasal obstruction, caused by septal deviation, there has been an increase in ENT complains among patients diagnosed with deviated nasal septum as such nasal obstruction can affect the ET function. With the ET being a tube connecting the middle ear cavity and the nasal cavity as well as providing middle ear ventilation. It therefore, acts as the controller of air pressure within the middle ear. It was also found that deviated nasal septum is responsible for ear fullness a condition that leads to changes in middle ear pressure and that carrying out septoplasty to correct the condition would improve middle ear pressure.

The clinicians should be aware of the septal pathologies in patients with frequent otologic problems as was the concluded by a study done by [Kaya et al.,2018] between March 30, 2015, and December 2015, at a tertiary care academic center, Turgut Ozal University. Fifty patients with deviated nasal septum were included using nose scale (questionnaire form for severity of nasal obstruction from 0 to 4), insufflations tests (Valsalva and Toynbyee) and tympanometry as an outcome tool. First tympanometry was performed on the morning of the operation. Initially, basal tympanogram was obtained. ET was considered to be functional when 10 decapascals (daPa) or a greater change in TPP was observed; if the alteration was less than $10 \mathrm{daPa}$, the ET function was considered to be poor. Measurements were repeated eight weeks after the operation. Comparison was done between two groups: one for the affected side ear and the other for the contra lateral ear. Statistical analysis proves that patients with isolated nasal septum deviation had lower middle ear pressure and worse ET functions at the side of deviation. After septoplasty, the number of functional ET increased and a statistically significant improvement in the middle ear pressure occurred. So they recommend that Before planning the middle ear surgery, full examination of the rhino-tubal unit and correct nasal septum deviation if the ear problem is found in the deviated side.

According to [Duran et al., 2014] a prospective randomized control study of 72 patients with severely deviated septum to determine the level of middle ear pressure and alterations in middle ear pressure levels after septoplasty using a tubal compliance tympanometric test during the Valsalva maneuver to find the relationship between deviated nasal septum surgery and tubal functions. The middle ear pressure values were divided into two groups; side of nasal obstruction (group 1) and opposite, non-affected side (group 2). Results showed improvement in the tubal opening pressure for the deviated side and contralateral side in the early and late post-septoplasty period. Despite the fact that this study was limited to a small sample size of the patients, the results showed $30 \%$ improvement rate on the affected sides and $10 \%$ improvement rate on non-affected side. The functioning of the ET has been found to be influenced by other factors such as airflow turbulence due to inflammation that may also cause ET dysfunction.

Another two studies show middle ear improvement after surgeries to correct causes of nasal obstruction, one of the studies done by [Abdel-Naby et al.,2014] on 30 patients with different nasal pathologies causing nasal obstruction as marked deviated septum was corrected by SMR procedure, chronic rhinosinusitis, antrochoanal polyp, chronic hypertrophic rhinitis, and bilateral nasal polyposis were investigated for the role of nasal surgery in changing ET function and middle ear ventilation. They used tubal function tests (Valsalva and Toynbee), and tympanometry. Ear fullness sensation was evaluated and the tests were performed Preoperatively and postoperatively after one month. Results showed that the postoperative results of ET function had improvements as compared to the preoperative results.

One of the studies done by [Salvinelli et al., 2005] on 40 patients, who underwent nasal surgery (septoplasty and/or inferior turbinate reduction) for nasal respiratory impairment caused by septal deviation and/or inferior turbinate hypertrophy, first evaluations of ETF in all patients were obtained with preoperative tympanometry, valsalva and toynbee, then repeated immediately before and after the removal of packs. furthermore, tympanometry and ETF tests were performed on the 2 weeks, 1 month and 3 months after the removal of packs. The results showed middle ear pressure on the 2 weeks, 1 month and 3 months after removal of packs was significant better than immediate pre and post packs removal $(\mathrm{p}=0,01)$,no significant difference was found between pre and post operative.

However, the prospective controlled study by [Sahin et al., 2014] at the Erciyes University in Turkey to investigate the effects of septoplasty on middle ear pressure and Eustachian tube function involving twenty-three patients and volunteers not complaining of nasal obstruction. They used the rhinomanometry, tympanometry, and Eustachian tube function tests (Valsalva and Toynbee) preoperatively and in the 1st and 3rd postoperative months for patients and control group. They results revealed that septoplasty did not affect middle ear pressure and Eustachian tube function. 
The prospective study done by [Rahim \& Fathollah, 2013] in Iran, on 70 patients, middle ear pressure and eustachian tube function on the septal deviated side and contralateral side before and after septoplasty (3 to 6 months later ) were measured through tympanmetry and eustachian tube function test (Toynbee test), the results showed that comparison between mean values of ear pressure in the deviated side and contralateral side has no significant difference before and after septoplasty.

Some results were obtained by [Akyildiz et al., 2017] using rhinomanometry, acoustic rhinometry and tympanomerty as tools to asses nasal function and ET function they made a caparison between study group and control group. They concluded that nasal septal deviation was highly associated with ET dysfunction and could be improved by nasal surgery. However nasal surgery itself caused ET dysfunction in the early postoperative period.

A study was done by [Eyigör H, 2013] from Turkey to evaluate the effects of septal deviation causing nasal obstruction and septal surgery on middle ear ventilation and pressure involving twenty five adult patients with DNS, used nose scale questionnaire to evaluate the severity of nasal obstruction preoperatively and postoperatively after 3 months . The first tympanometry was performed preoperatively and postoperatively after 7 days, 1 month and 3 months. They showed that deviated nasal septum had no significant effects on the changes in middle ear pressure and ventilation as the difference between the preoperative and the postoperative nose score remained significant for the third month.

The first report on the relationship between ET function and middle ear pressure a study was done by [bonding \& Tos, 1981] to investigate middle ear pressure by tympanometry. The study done on patients with different causes of nasal blockage, patients with unilateral anterior nasal packing, this show no significant change in the middle ear pressure but patient with bilateral anterior nasal packing, unilateral posterior packing or patient with infectious mononucleosis, show significant change middle ear pressure.

[Yilmaz et al., 2012] found a higher decrease in the acoustic impedance values of the Merocel nasal pack group compared with the internal nasal splint group and stated that the Merocel nasal packings cause eustachian dysfunction by preventing air flow. There are different opinions on the etiopathogenesis of Eustachian tube dysfunction caused by intranasal packings after nasal surgery. Two studies conclude same results [Şereflican et al., 2015] study done on 60 patients and [Johannessen J \& Poulsen P, 2014] on 27 patients.

In our study, there we did not measure the effect of nasal packing on changing middle ear pressure as all postoperative measurement of tympanometry were done after removal of nasal packing and internal nasal splint.

Therefor, based on our data and review the literature septoplasty showed no significant change on middle ear pressure and ETF.

\section{Materials and Methods:-}

This study was carried out at the otolaryngology department of King Abdulaziz University Hospital in Jeddah from January 2019 to April 2019. An overall of 30 adult patients with range age from 18-60 with DNS and requiring septoplasty at the hospital were included in this study. Patients reporting other causes of ET dysfunction causes such as nasal polyps, sinusitis and allergic rhinitis and those that had previously undergone septoplasty, tympanoplasty, TM perforation, middle ear diseases, external ear diseases and sinus surgery were excluded from the study. Informed consent was obtained from all eligible participants who met the inclusion criteria. Human subject approval was obtained from King Abdulaziz University Hospital institutional review board. 30 patients included in this study underwent detailed history taking, nasal, ear and nasopharyngeal examination.

The middle ear pressure values at both side of nasal obstruction and opposite side are determine by tympanometry performed 1 day before the surgery, then 1week post septoplasty and 1month post septoplasty. Compared between middle ear pressure values before and after septoplasty collection.

\section{Results:-}

1. The data collected from the patients entered in to the Statistical Package for social science program (SPSS). Suitable statistical methods including the descriptive and inferential statistics employed. 
Table 1:- Difference in middle ear pressure value between same sides and contralateral of right nasal deviation.

\begin{tabular}{|l|l|l|}
\hline Right nasal deviation & Median & P value \\
\hline Pressure in same side & -48. & \\
\hline Pressure in contralateral side & -48. & .755 \\
\hline
\end{tabular}

There was no significant difference in pressure between the left ear and right ear in right nasal deviation ( $\mathrm{P}$ value) is (0.755).

Table 2:- Difference in middle ear pressure value between same sides and contralateral of left nasal deviation.

\begin{tabular}{|l|l|l|}
\hline Left nasal deviation & Median & P value \\
\hline Pressure in contralateral & -36. & \\
\hline pressure in same side & -40. & .461 \\
\hline
\end{tabular}

There was no significant difference in pressure between the left ear and right ear in left nasal deviation $\mathrm{P}$ value (0.461).

The results in (table 1) and (table 2) reveal that there is no statistically significant difference in middle ear pressure between same sides and contralateral of deviated nasal septum, due to (p-value) is greater than (0.05) level. Thus, we conclude that the deviated nasal septum has no effect on middle ear pressure.

Table 3:- Right side septum deviation.

\begin{tabular}{|l|l|l|l|l|}
\hline & $\begin{array}{l}\text { Right side median } \\
\text { pressure (same side) }\end{array}$ & P value & $\begin{array}{l}\text { Left side median pressure(opposite } \\
\text { side) }\end{array}$ & P value \\
\hline Pre op & -48. & Reference & -48 & Reference \\
\hline $\begin{array}{l}\text { Post op 1, one } \\
\text { week }\end{array}$ & -44 & 0.413 & -48 & 0.233 \\
\hline $\begin{array}{l}\text { Post op 2, one } \\
\text { month }\end{array}$ & -48. & 0.842 & -48 & 0.408 \\
\hline
\end{tabular}

1. A-Right ear pressure (same side): The median pressure was -48 before operation and -44 at one week post operation with approximately $8 \%$ change. However this difference was not significant $(\mathrm{p}$ value $=0.413$ ) The median pressure after one month post operation was -44 and it has no significant difference with the pressure before operation ( $\mathrm{p}$ value $=0.842$ ).

2. B- Left side pressure (opposite side): The median pressure was -48 before operation and -48 at one week post operation with no significant difference between them ( $\mathrm{p}$ value $=0.233$ ). The median pressure one month after operation was -48 which is not significantly different from the pressure before the operation $(\mathrm{p}$ value $=0.408)$.

Table 4:- Left side septum deviation.

\begin{tabular}{|l|l|l|l|l|}
\hline & $\begin{array}{l}\text { Left side median } \\
\text { Pressure(same side) }\end{array}$ & P value & $\begin{array}{l}\text { Right side median Pressure } \\
\text { (opposite side) }\end{array}$ & P value \\
\hline Pre op & -40 & Reference & -36 & Reference \\
\hline $\begin{array}{l}\text { Post op 1, one } \\
\text { week }\end{array}$ & -44 & 0.373 & -40 & 0.623 \\
\hline $\begin{array}{l}\text { Post op 2, one } \\
\text { month }\end{array}$ & -40 & 0.726 & -52 & 0.670 \\
\hline
\end{tabular}

1. A- Left side pressure (same side): The median pressure was -40 before operation and -44 at one week post operation with approximately $10 \%$ change. However this difference was not significant ( $\mathrm{p}$ value $=0.373$ ). The median pressure one month after operation was -40 which is not significantly different from the pressure before the operation $($ median $=-40)$ and $(\mathrm{p}$ value $=0.726)$.

2. B- Right side pressure (opposite side): The median pressure was -36 before operation and -40 at one week post operation with approximately $11 \%$ change. However this difference was not significant ( $\mathrm{p}$ value $=0.623$ ). The median pressure one month after operation was -52 with approximately $23 \%$ change. However this difference was not significant $(\mathrm{p}$ value $=0.670$ )

The results in tables 3 and 4 show that, there is no statistically significant change between pre.Op and post. Op in first week and after one month in the level of pressure for the same side of deviated nasal septum and opposite side. which means that there is no improvement in middle ear pressure. This also support that there is no side effect of the operation. 


\section{Discussion:-}

The effect of septoplasty on middle ear pressure among patients with deviated nasal septum remains controversial. Currently in Saudi Arabia no researches had been done regarding this topic yet and the expected benefits of septoplasty on improving middle ear pressure need to be evaluated more.

Nose, paranasal sinuses, and nasopharyngeal diseases can disrupt the functions of the ET. Among the studies that have investigated the effects of nasal obstruction on ET functions, the clinical study by [bonding \& Tos, 1981] Show that middle ear pressure changes occur with double-sided total nasal obstruction. Nasal septum deviation affects more than 80 percent of the world population with most people with different symptoms range from nasal obstruction to ET dysfunction. Other causes of nasal obstruction include: choanal atresia, traumatic fracture nose, septal hematoma or abscess, allergic rhinitis, antrochonal polyp, nasal polyposis, adenoid hypertrophy and nasal tumors. Many different tools are used for evaluation of nasal obstruction. Thses include: compelet history taking ,nose scale questionnaire, clinical examination by anterior rhinoscopy and endoscopic examination and radiological assessment and objectively by rhinomerty and acoustic rhinomanometry.

Despite the fact that the prevalence of nasal septal deviation reaches up to $80 \%$, only a minority of affected individuals suffer from nasal obstruction. Some of the articles in the literature dealt with the effect of deviated nasal septum on middle ear pressure. In that context, [Nanda et al.,2017], [Duran et al., 2014], [Akyildiz et al., 2017] and [Kaya et al.,2018] had shown that among the common causes of nasal obstruction is a nasal septum deviation which has proved to have negative effects on the middle ear pressure as well as ventilation.

Looking at the literatures, the role of septoplasty in changing middle ear pressure and ventilation showed no significant change in studies done by [Eyigör H, 2013], [Salvinelli et al., 2005], [Rahim \& Fathollah, 2013] and [Sahin et al., 2014].

In our study, all thirty patients underwent the closed technique approach as this method routinely used by in ENT Department in KAUH in Jeddah, Saudi Arabia.

Some of studies such as [Yilmaz et al., 2012], [Johannessen J \&Poulsen, 2014] and [Şereflican et al., 2015],compare the effect of nasal packing and internal nasal splints on changing middle ear pressure and conclude that merocel packing may cause transient affection on ET functions and the internal nasal splint is more comfortable than merocel nasal packing.

Nonetheless, none of these reports the role of Septoplasty in changing middle ear Ventilation and pressure in Saudi Arabia.

In my study, I aimed to evaluate middle ear pressure in side of deviated nasal septum and compare it to the opposite side then to determine the effect septoplasty on middle ear pressure values at both sides of deviated nasal septum and opposite side with excluding any patients with additional pathologies other than septum deviation.

\section{Conclusions and Recommendations:-}

In conclusions, this is the first study to report the effect septoplasty on middle ear pressure among patients with deviated nasal septum in Saudi Arabia, our results correlate with many of international studies that there was no significant effect of septoplasty on middle ear pressure among patients with deviated nasal septum. More clinical studies required to find out the effects of nasal septal surgeries on middle ear pressure. Future efforts should concentrate on developing well-designed controlled human studies on broad basis and large sample of patients in order to provide more statistically valuable results.

\section{Ethical considerations:}

Administrative approval was obtained from the Biomedical Ethics Research Committee unit. Ethical approval was obtained from the Ethical Committee of the Faculty of Medicine, King Abdulaziz University (Reference No 26-19) Prospective study. 


\section{References:-}

1. Etigadda D, Majeed J. Clinical and Radiological Evaluation of Deviated Nasal Septum in Classifying and Surgical Management of the Deviated Septums. IOSR Journal of Dental and Medical Sciences. 2017;16(2):1320

2. Demirci S, Ertan N, Tuzuner A, Ozcan M. Correlation Between the Septal Body and theNasal Turbinates in Patients With Deviated Nasal Septum. Journal of CraniofacialSurgery. 2016;27(1):166-169

3. Rajesh R. A Study on the Relationship of Deviated Nasal Septum with Middle Ear Pressure among Patients treated in a Tertiary Care Centre. Journal of Evolution of Medical and Dental Sciences. 2017;6(16):1235-1238.

4. Grants atlas of anatomy by Anne M.R.Agur\&Arthu F Dalley 987654321 for Library of Congress ISBN 97814698906852017.

5. Kaya M, Dağlı E, Kirat S. Does Nasal Septal Deviation Affect the Eustachian Tube Function and Middle Ear Ventilation?Turk Arch Otorhinolaryngol.2018 Jun;56(2):102-105. doi: 10.5152/tao.2018.2671.Epub 2018 Jun

6. Roblin DG, Eccles R. What, if any, is the value of septal surgery? Clin Otolaryngol Allied Sci 2002; 27: 77-80.

7. Kamal daghistani. Nasal Septal Deviation in Saudi patients a Hospital Based Study 2002;10:39-46.

8. Nanda M, Kaur M, Bhatia S. Impact of Septoplasty on hearing and middle ear function. International Journal of Research in Medical Sciences. 2017;6(1):135.

9. Kaya M, Dağlı E, Kırat S. Does Nasal Septal Deviation Affect the Eustachian Tube Function and Middle Ear Ventilation?Turk Arch Otorhinolaryngol.2018 Jun;56(2):102-105. doi: 10.5152/tao.2018.2671.Epub 2018 Jun

10. Duran, K., Fatih, Y., \& Doğan. "Middle Ear Pressure After Septoplasty." Journal of Craniofacial Surgery, vol. 25, no. 1, 2014, pp. e19-e21, doi:10.1097/scs.0b013e3182a2ed3d

11. Abdel-Naby Awad O,El-Badry M, Salama Y.Effect of nasal obstruction surgery on middle ear ventilation. The Egyptian Journal of Otolaryngology. 2014;30(3):191.

12. Salvinelli F, Casale M, Greco F, D'Ascanio L, Petitti T, Di Peco V. Nasal surgery and Eustachian tube function: effects on middle ear ventilation. Clin Otolaryngol 2005; 30: 409-13.

13. Sahin M, Gulec S, Perisan U, Kulahli I. Does Septoplasty Affect Middle Ear Pressure and Eustachian Tube Function?. Erciyes Tip Dergisi/Erciyes Medical Journal. 2014;36(3):115-118.

14. Rahim Davari, Fathollah Behnoud.The effect of nasal obstruction surgery (septoplasty) on eustachian tube function and middle ear pressure 2014,14(4): 322-330

15. Akyildiz MY, Özmen ÖA, Demir UL, Kasapoğlu F, Coşkun HH, Basut OI, et al. Impact of septoplasty on Eustachian tube functions. J Craniofac Surg 2017; 28: 1929-32.

16. Eyigör $\mathrm{H}$. The effect of operation success on middle ear ventilation in patients with nasalseptal deviation. The Turkish Journal of Ear Nose and Throat. 2013;23(1):26-31.

17. Bonding $\mathrm{P}$, Tos $\mathrm{M}$. middle ear pressure during brief pathological conditions of the nose and throat. Acta Otolaryngol. 1981;92 (1-2):63-9.

18. Yilmaz MS, Guven M, Buyukarslan DG, Kaymaz R, Erkorkmaz U. Do silicone nasal septal splints with integral airway reduce postoperative Eustachian tube dysfunction? Otolaryngol Head Neck Surg 2012; 146: 141-5.

19. Şereflican M, Yurttaş V, Oral M, Yılmaz B, Dağlı M. Is middle ear pressure affected by nasal packings after septoplasty? J Int Adv Otol 2015; 11: 63-5.

20. Johannessen J, Poulsen P. The influence of anterior nasal packings on middle ear pressure Acta 2014 MarApr;97(3-4):363-4. 